\title{
GEOMAGNETIC SURVEY ON SINJSKO POLJE REPEAT STATION AND DATA REDUCTION USING THE ONSITE dIdD VARIOMETER
}

\author{
Danijel Šugar, András Csontos, Mario Brkić
}

Original scientific paper

Within the Croatian-Hungarian project for the first time in the Republic of Croatia the repeat stations survey was carried out using an onsite dIdD (delta Declination / delta Inclination) variometer. Since the geomagnetic field vector observations are obtained in the instrument's reference frame, the calibration parameters have to be determined enabling the transformation to the geographic coordinate system XYZ. Three and a half days long occupation of the Sinjsko polje (SINP) repeat station revealed the temporal variability of the geomagnetic field gradients. Although observations were affected by extra magnetic field contributions, the determination of the quiet-time level geomagnetic field differences between the SINP repeat station and THY (Tihany) reference observatory enabled a more reliable data reduction. The comparison of results of different data reduction methods pointed out the improvement of the geomagnetic survey with the onsite variometer.

Keywords: calibration parameters; data reduction; dIdD; geomagnetic survey; onsite variometer; repeat station

\section{Geomagnetska izmjera na sekularnoj točki Sinjsko polje i redukcija mjerenja upotrebom terenskog dldD variometra}

Izvorni znanstveni članak

U sklopu hrvatsko-mađarskog projekta po prvi puta u Republici Hrvatskoj geomagnetska izmjera izvedena je upotrebom terenskog dIdD (delta Inklinacija / delta Deklinacija) variometra. S obzirom da su opažanja vektora geomagnetskog polja dobivena u referentnom okviru instrumenta, potrebno je odrediti kalibracijske parametre čime se omogućuje transformacija u geografski koordinatni sustav XYZ. Tri i pol dana trajanja izmjere na sekularnoj točki Sinjsko polje (SINP) otkrilo je vremensku promjenjivost gradijenata geomagnetskog polja. Iako su opažanja bila pod utjecajem doprinosa dodatnog magnetskog polja, određivanje mirne razine razlika geomagnetskog polja između sekularne točke SINP i referentnog opservatorija THY (Tihany) omogućilo je pouzdaniju redukciju. Usporedba rezultata različitih metoda redukcija ukazala je na poboljšanje geomagnetske izmjere korištenjem terenskog variometra.

Ključne riječi: dIdD; geomagnetska izmjera; geomagnetska sekularna točka; kalibracijski parametri; redukcija opažanja; terenski variometar

\section{Introduction}

In the Republic of Croatia the geomagnetic field has been periodically observed and monitored on the stations of the Croatian Geomagnetic Repeat Stations Network (CGRSN) (Fig. 1).

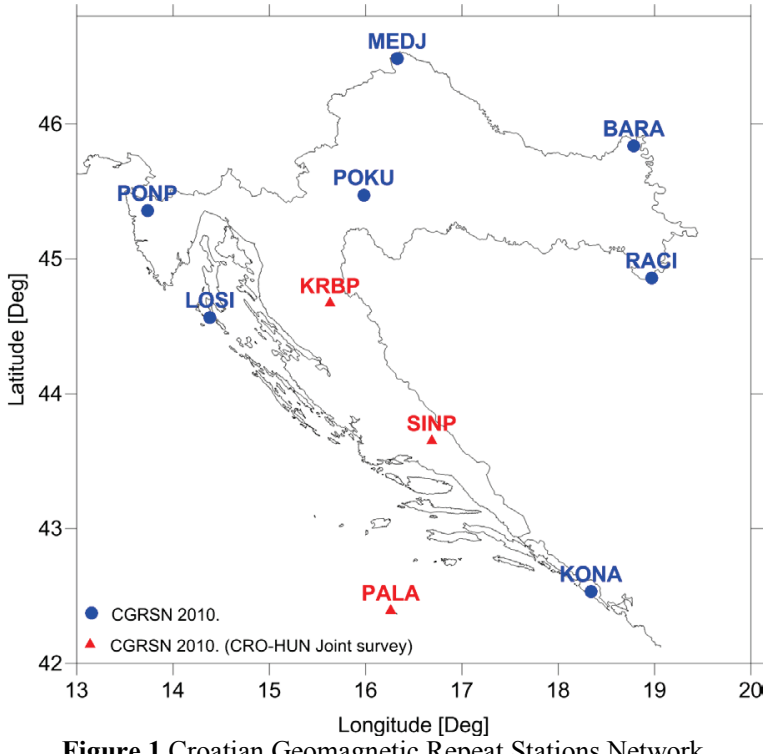

Figure 1 Croatian Geomagnetic Repeat Stations Network

The network was designed according to IAGA (International Association of Geomagnetism and Aeronomy) criteria [1] as well as recommendations of the MagNetE (Magnetic Network in Europe) working group [2]. In the vicinity of the repeat station (RS), usually in North-East or East point of the outer grid for gradient determination, the auxiliary station (AUX) was monumented. During declination $D$ and inclination $I$ observations on the repeat station, the total field intensity $F$ was observed on the AUX station. After the network setup completion, the average distance between repeat stations was approximately $178 \mathrm{~km} \mathrm{[3].}$

The whole CGRSN was surveyed every year in the period between 2007 and 2010 [4]. All these surveys enabled the determination of the geomagnetic elements secular variation over the Croatian territory, see e.g. [5], [6], [3] and [7]. Declination $D$ and inclination $I$ were observed by the null-method using the nonmagnetic theodolite Zeiss Theo 010B with fluxgate probe and electronic unit Bartington Mag- $010 \mathrm{H}$, the total field intensity $F$ was observed with GEM System GSM-19G Overhauser PPM (Proton Precession Magnetometer). Coordinates of the repeat stations as well as the azimuth reference marks were determined by the GNSS (Global Navigation Satellite System) methods and subsequently the ellipsoidal azimuths were calculated. GNSS observations according to unique methodology were carried out on the repeat stations and azimuth reference marks, simultaneously with the geomagnetic survey in 2010. After the vector baselines processing and geodetic network adjustment, the coordinates were obtained in CTRS96 (Croatian Terrestrial Reference System 1996) and azimuth values determined in reference to the GRS 80 (Geodetic Reference System 1980) ellipsoid [8].

Before each survey, geomagnetic instruments were checked and compared with the observatory standard. Since 2007 the nonmagnetic theodolite Zeiss Theo 010B was regularly checked in the Laboratory for Measurements and Measuring Technology of the Faculty 
of Geodesy of the University of Zagreb and subsequently compared at the geomagnetic observatory Tihany in Hungary. The successful cooperation between Faculty of Geodesy and Geological and Geophysical Institute of Hungary (former Eötvös Loránd Geophysical Institute of Hungary -ELGI) continued through the project 'Joint Croatian-Hungarian Geomagnetic Repeat Stations Survey and Joint Geomagnetic Field Model' [9], [10], [11] and [12]. Stations surveyed within the project were KRBP (Krbavsko polje), SINP (Sinjsko polje) and PALA (Palagruža) in Fig. 1 designated with red triangles. That was the opportunity to carry out the geomagnetic survey using the onsite dIdD (delta Declination / delta Inclination) variometer for the first time in the Republic of Croatia. Absolute measurements were performed with DIM (Declination-Inclination Magnetometer) instrument (Zeiss Theo 020 A theodolite equipped by DMI D\&I fluxgate) of ELGI. Results and analysis given in the sequel are based on the survey carried out on the SINP repeat station in the period 23-27 July 2010.

\section{Basics of the dldD variometer}

The dIdD is a vector magnetometer used for the continuous monitoring of the geomagnetic field elements. It consists of double mutually perpendicular coils system measuring one unbiased and four biased total intensity magnetic fields. The coil axes are oriented nearly perpendicular to the total intensity magnetic field vector i.e. the axis of the $D$-coil is horizontal and the axis of the $I$-coil lies in the vertical plane of the magnetic meridian. Actually, the dIdD system consists of three magnetic axes: two physically defined by the $D$-coil and $I$-coil and the third S-axis (Sensor) which is mathematically defined to be perpendicular to both coil axes. Moreover, the $S$ axis is directed parallel to the field, while the $D$-coil axis is directed toward magnetic East and $I$-coil is directed so that the $S-D-I$ axes form a right-handed system [13]. Assuming that $\hat{\boldsymbol{S}}, \hat{\boldsymbol{D}}$ and $\hat{\boldsymbol{I}}$ are unit vectors along the $S, D$ and $I$ axes, respectively, the relation $\hat{\boldsymbol{S}} \times \hat{\boldsymbol{D}}=\hat{\boldsymbol{I}}$ is fulfilled.

One cycle of the dIdD measurements consists of 5 readings: $F$ (undeflected total intensity), $D+$ (total intensity deflected parallel to the $D$-axis), $D$ - (total intensity deflected antiparallel to the $D$-axis), $I+$ (total intensity deflected parallel to the $I$-axis), $I$ - (total intensity deflected antiparallel to the $I$-axis). The total intensity vector deflected parallel to the $D$-axis is given as a vector superposition of the total intensity vector and vector generated by the $D$-coil. From the dIdD measurements, the $A_{\mathrm{i}}$ and $A_{\mathrm{d}}$ (deflection fields generated by the $I-$ and $D$ coil, respectively) as well as the dIdD vector components $B_{\mathrm{i}}, B_{\mathrm{d}}$ and $B_{\mathrm{s}}$ (along the $I, D$ and $S$ axes, respectively) can be inferred according to expressions given in e.g. [13].

Generally, the $D$ - and $I$-coil axes are not mutually orthogonal, thus the orthogonality error has to be determined. The procedure includes the record of $5 \mathrm{sec}$ long sequence of readings: $F, D+I+, D-I-, F$ and $F, D-I+$, $D+I-, F$ where, $D+I+, D-I-, D-I+, D+I-$ are the total field values deflected by the $I$ and $D$-coils jointly in parallel or antiparallel sense [9]. Using readings of the record sequence, the orthogonality error $\varepsilon_{\mathrm{ID}}$ can be calculated by expressions given in e.g. [14]. As the final result of the orthogonalization procedure the orthogonal magnetic field dIdD components $B_{\mathrm{ic}}, B_{\mathrm{dc}}$, and $B_{\mathrm{sc}}$ are obtained.

The 3-axis fluxgate magnetometers are the most frequently used vector magnetometers in the current observatory practice [13]. For the calibration fluxgate device twelve parameters have to be determined, namely, three offsets, three scale factors, three orthogonality errors and three orientation parameters (ibid.). Since the dIdD system is based on the function of a nuclear magnetometer [15], the scale factors and offsets do not need to be calibrated [13]. Thus, only the following four parameters have to be calibrated in order to determine the reference frame of the dIdD magnetometer: rotation angles $I_{0}, D_{0}$ and $\varepsilon_{0}$ (explained in the next chapter) as well as the orthogonality error of magnetic axes $\varepsilon_{\mathrm{ID}}$.

\section{Reference frame of the dIdD variometer}

Components of total intensity magnetic field vector $\left(B_{\mathrm{i}}, B_{\mathrm{d}}, B_{\mathrm{s}}\right)$ as well as their orthogonalized components $\left(B_{\mathrm{ic}}, B_{\mathrm{dc}}, B_{\mathrm{sc}}\right)$ are related to the dIdD reference frame. Since components of the geomagnetic field are usually given in the $X Y Z$ system, by consecutive rotations about $S-D-I$ axes the reference frame of the dIdD is transformed to the geographic system $X Y Z$. The $X Y Z$ system is a righthanded orthogonal system where the $X$ is the horizontal axis directed to the geographic North, $Y$ is the horizontal axis perpendicular to the $X$ axis and directed to the geographic East and the $Z$ axis is positive to the astronomic nadir direction [15].

In the first step, the orthogonal dIdD reference frame is rotated by $\varepsilon_{0}$ about the $S$ axis in clockwise direction when looked from positive side of the $S$ axis toward the origin. This step corresponds to the levelling of the $D$-coil axis. The rotation matrix is given by [13]:

$$
\boldsymbol{E}_{0}=\left[\begin{array}{ccc}
1 & 0 & 0 \\
0 & \cos \varepsilon_{0} & -\sin \varepsilon_{0} \\
0 & \sin \varepsilon_{0} & \cos \varepsilon_{0}
\end{array}\right]
$$

The next rotation by $I_{\mathrm{o}}$ about the $D$-coil axis, in a counterclockwise direction when looked from positive side of $D$ axis toward the origin, brings the $B_{\text {ic }}$ vector horizontal and $B_{\mathrm{sc}}$ vector vertical. The resulting coordinate frame corresponds to the HDZ (Horizontal, Declination, vertical $Z$ component)) system (ibid.):

$$
\boldsymbol{I}_{0}=\left[\begin{array}{ccc}
\cos I_{0} & 0 & -\sin I_{0} \\
0 & 1 & 0 \\
\sin I_{0} & 0 & \cos I_{0}
\end{array}\right]
$$

Finally, the rotation by $D_{\mathrm{o}}$ about the $I$-coil axis in the clockwise direction when looked from positive side of the $I$ axis toward the origin, transforms the HDZ system to a geographic $X Y Z$ system (ibid.):

$$
\boldsymbol{D}_{0}=\left[\begin{array}{ccc}
\cos D_{0} & -\sin D_{0} & 0 \\
\sin D_{0} & \cos D_{0} & 0 \\
0 & 0 & 1
\end{array}\right] .
$$


The transformation from the $\mathrm{dIdD}$ reference frame to the $\mathrm{XYZ}$ reference frame is given by the matrix equation

$$
\boldsymbol{B}_{x y z}=\boldsymbol{D}_{0} \boldsymbol{I}_{0} \boldsymbol{E}_{0} \boldsymbol{B}_{\text {sdi_corr }}
$$

where

$$
\boldsymbol{B}_{\text {sdi_corr }}=\left[\begin{array}{c}
B_{s c} \\
B_{d c} \\
B_{i c}
\end{array}\right],
$$

is the vector of the orthogonal magnetic field components given in the $\mathrm{dIdD}$ reference frame (ibid.).

The matrix Eq. (4) can be unfolded leading to the nonlinear equation system $(6 \div 8)$ :

$$
\begin{aligned}
& X=B_{s c} \cos D_{0} \cos I_{0}- \\
& -B_{d c}\left(\cos D_{0} \sin I_{0} \sin \varepsilon_{0}+\sin D_{0} \cos \varepsilon_{0}\right)- \\
& -B_{i c}\left(\cos D_{0} \sin I_{0} \cos \varepsilon_{0}-\sin D_{0} \sin \varepsilon_{0}\right), \\
& Y=B_{s c} \sin D_{0} \cos I_{0}- \\
& -B_{d c}\left(\sin D_{0} \sin I_{0} \sin \varepsilon_{0}-\cos D_{0} \cos \varepsilon_{0}\right)- \\
& -B_{i c}\left(\sin D_{0} \sin I_{0} \cos \varepsilon_{0}+\cos D_{0} \sin \varepsilon_{0}\right), \\
& Z=B_{s c} \sin I_{0}+B_{d c} \cos I_{0} \sin \varepsilon_{0}+B_{i c} \cos I_{0} \cos \varepsilon_{0} .
\end{aligned}
$$

From the declination $D$ and inclination $I$ observed at the repeat station along with the total intensity $F$ observed at the auxiliary station and subsequently reduced to the repeat station using the previously determined difference $\Delta F$ (AUX-RS), the absolute components of the magnetic field vector at the repeat station are calculated as follows [15]:

$$
\begin{aligned}
& H=F \cos I, \\
& X=H \sin D, \\
& Y=H \cos D, \\
& Z=F \sin I .
\end{aligned}
$$

Similarly, the $X Y Z$ components at the dIdD station are determined from the system of nonlinear Eq. $(6 \div 8)$ using the initial approximate orientation parameter values $D_{0}$ and $I_{0}$ obtained from the first absolute set at the repeat station and assuming that the $D$-coil axis was horizontal i.e. $\varepsilon_{0}=0$ and the axes of coils were orthogonal i.e. $\varepsilon_{\mathrm{ID}}=0$.

The baseline value is a value which has to be added to the data produced by the variometer to obtain the final absolute value of the magnetic field component [15]. The baseline values are commonly defined as the difference of the components determined from the absolute sets (ABS) at the repeat station and $\mathrm{dIdD}$ variometer station (VAR):

$$
\begin{aligned}
& X_{\text {base }}=X_{\mathrm{abs}}-X_{\mathrm{var}}, \\
& Y_{\text {base }}=Y_{\mathrm{abs}}-Y_{\mathrm{var}}, \\
& Z_{\text {base }}=Z_{\mathrm{abs}}-Z_{\mathrm{var}} .
\end{aligned}
$$

where $X_{\mathrm{abs}}, Y_{\mathrm{abs}}$ and $Z_{\mathrm{abs}}$ are the components obtained from the absolute measurements while $X_{\mathrm{var}}, Y_{\mathrm{var}}$ and $Z_{\mathrm{var}}$ are the mean component values at moments corresponding to the specific instrument positions during declination $D$ and inclination $I$ observations by the null-method (e.g. the time $t_{\text {Nup }}$ corresponds to the North-up position of inclination observation) [16]:

$$
\begin{aligned}
& X_{\mathrm{var}}=\left[X_{\mathrm{var}}\left(t_{\mathrm{Nup}}\right)+X_{\mathrm{var}}\left(t_{\mathrm{Sdn}}\right)+X_{\mathrm{var}}\left(t_{\mathrm{Ndn}}\right)+X_{\mathrm{var}}\left(t_{\mathrm{Sup}}\right)\right] / 4, \\
& Y_{\mathrm{var}}=\left[Y_{\mathrm{var}}\left(t_{\mathrm{Eup}}\right)+Y_{\mathrm{var}}\left(t_{\mathrm{Wup}}\right)+Y_{\mathrm{var}}\left(t_{\mathrm{Edn}}\right)+Y_{\mathrm{var}}\left(t_{\mathrm{Wdn}}\right)\right] / 4, \\
& Z_{\mathrm{var}}=\left[Z_{\mathrm{var}}\left(t_{\mathrm{Nup}}\right)+Z_{\mathrm{var}}\left(t_{\mathrm{Sdn}}\right)+Z_{\mathrm{var}}\left(t_{\mathrm{Ndn}}\right)+Z_{\mathrm{var}}\left(t_{\mathrm{Sup}}\right)\right] / 4 .
\end{aligned}
$$

Subtracting the baseline values from the absolute components according to Eq. (10) gives the $X Y Z$ components as they were observed at the $\mathrm{dIdD}$ station (spatial reduction from the repeat station to the VAR station). From $X Y Z$ components reduced to the VAR station and the relations in Eq. $(6 \div 8)$, the $\mathrm{dIdD}$ calibration parameters can be determined.

\subsection{Determination of the calibration parameters}

During the SINP repeat station occupation the absolute measurements were performed in altogether 33 sets distributed in four evening and three morning sessions [17]. From all 33 absolute sets observed at the repeat station and subsequently reduced to the VAR station, sets exhibiting maximal differences in the observed declination $D$, inclination $I$ and vertical component $Z$ were selected. The absolute sets with maximal differences in observed geomagnetic elements provide a reliable numerical solution [18]. Besides the maximal differences in the observed quantities, the sets for the calibration parameters determination were selected taking into consideration the reliability of the obtained baselines components as well as the calculated misalignment errors $\left(\delta_{\mathrm{D}}, \varepsilon_{\mathrm{I}}\right)$ and offset of electronics and sensor $\left(A_{0 \mathrm{D}}, A_{0 \mathrm{I}}\right)$. The misalignment errors of the optical axis of the theodolite telescope and the fluxgate probe axis in the horizontal and vertical plane $\left(\delta_{\mathrm{D}}\right.$ and $\varepsilon_{\mathrm{I}}$, respectively) as well as the offset of electronics and sensor in the horizontal and vertical plane were calculated according to the expressions given in [15] and [16]. The selected absolute sets involved in the calibration parameters computation were sets \#3-8-13-21-27 exhibiting maximal differences during observations. The estimation of the approximate value needed for the numerical computation of the calibration parameters was obtained by expressions given in [13].

In order to reach the 10 arc second accuracy of the levelling error $\varepsilon_{0}$, the absolute components must be measured with $0,01 \mathrm{nT}$ accuracy [9]. This accuracy can be seldom achieved, especially in the case of the $Y$ component which is, moreover, barely sensitive to the levelling error of the $\mathrm{dIdD}$ in comparison to the $X$ and $Z$ components (ibid.). This is the reason why the calibration parameters determination was carried out considering the $X$ and $Z$ components only.

The numerical values of the calibration parameters are given as follows: $\varepsilon_{0}=0,2923^{\circ}, I_{0}=60,7292^{\circ}$ and $D_{0}=$ $2,5633^{\circ}$.

The orthogonality error was determined from observations taken at the beginning and at the end of the SINP repeat station occupation. The average value of two 
determinations with its precision estimation is given as follows: $\varepsilon_{\mathrm{ID}}=4,511^{\prime} \pm 0,048^{\prime}$. The procedure of the orthogonality error calculation was presented in e.g. [14].

\section{Determination of the dldD baselines}

For the purpose of calibration parameters determination at the $\mathrm{dIdD}$ station, it was necessary to spatially reduce the geomagnetic elements from the repeat station to the variometer station. The distance between the repeat station and the variometer station was approximately $530 \mathrm{~m}$ and the total field difference $\Delta F(\mathrm{VAR}-\mathrm{RS})$ was on the average $0,41 \mathrm{nT}$. The small spatial gradient of the total field $F$ between the repeat station and the dIdD station led us to conclude the same for the component differences. The spatial reduction was performed by subtraction of the baseline values from the corresponding absolute geomagnetic component. Similarly, after the calibration parameters determination and $X Y Z$ component calculations at the dIdD station, it was necessary to reduce the geomagnetic field elements $(X Y Z F)$ back to the repeat station i.e. they must be related to the repeat station enabling the subsequent comparison with reference observatory data as well as the data reduction. The $X Y Z$ baselines of the $\mathrm{dIdD}$ were determined with definitive values of the calibration parameters (Tab. 1), in Fig. 2 are shown $Y$ and $F$ baselines exhibiting the maximal (range 10,19 nT) and minimal (range $0,43 \mathrm{nT}$ ) time variability, respectively.

The time variability of the baselines values i.e. the time dependence of the gradients of the $Y$ component and total intensity $F$ between the repeat station and dIdD station is promptly visible (Fig. 2). Since for both baselines were given the best-fit lines, it is obvious that the time dependence is present in $Y$ and $F$ baseline, most prominently in the $Y$ component. Such behaviour of baselines represents a limitation for the calibration parameters determination procedure, moreover it significantly affects the reliability of the calibration parameter results. Because of its strong temporal variability, the $Y$ baseline component was not included in the calibration parameters determination.

During the KRBP repeat station occupation in the period $19 \div 23$ July 2010 a significant temporal variability of baselines was noticed but, fortunately, only for the $Y$ component [9]. One of the possible explanations for the observation of the temporal change of the magnetic field gradient can be a significant conductivity contrast between the Adriatic Sea and the mainland that can result in spatial field variation in small spatial and temporal scales, even in large distances (ibid.). In comparison, the baseline values at the observatories change very slowly, thus the same value with an accuracy better than $0,25 \mathrm{nT}$ is often valid for weeks [15].
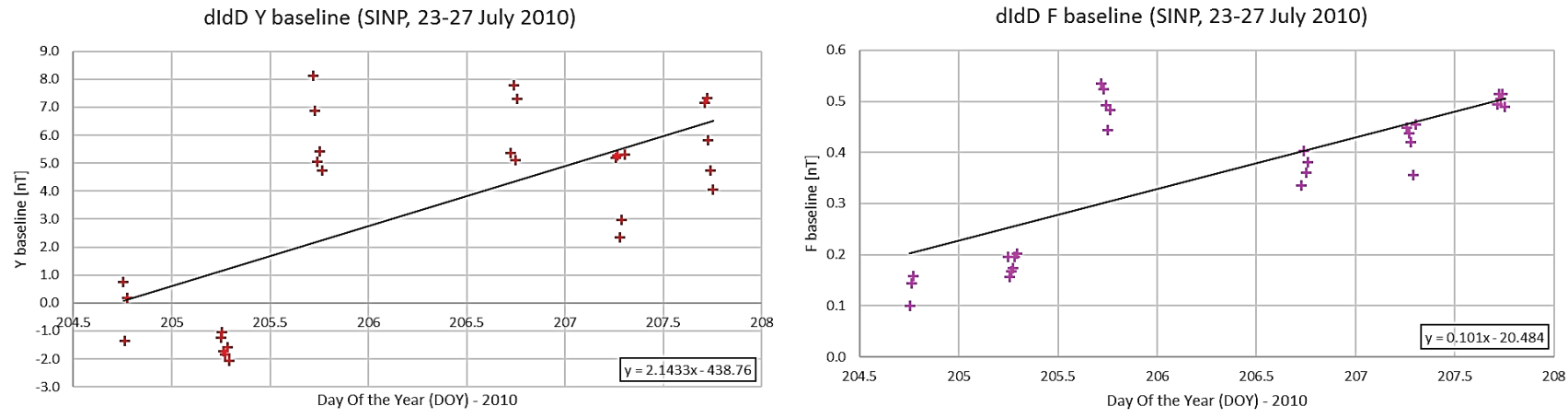

Figure 2 From left to right: $Y$ and $F$ dIdD baselines during the SINP repeat station occupation in the period $23 \div 27$ July 2010 ;

$Y$ baseline exhibited maximal while $F$ baseline exhibited minimal temporal variability

Analysing the graphical representation of the $Y$ and $F$ baselines shown in Fig. 2 and the statistical quantities of baselines $(X Y Z F)$ presented in Tab. 1, it could be concluded that the observations were affected by an anomalous magnetic field source. The distance between SINP repeat station and the Adriatic Sea coast is only 20 $\mathrm{km}$.

Table 1 Statistics of the $X Y Z F$ dIdD baselines during the SINP repeat station occupation in the period $23 \div 27$ July 2010

\begin{tabular}{|c|c|c|c|c|}
\hline $\begin{array}{c}\text { Baseline } \\
\text { component }\end{array}$ & $X / \mathrm{nT}$ & $Y / \mathrm{nT}$ & $Z / \mathrm{nT}$ & $F / \mathrm{nT}$ \\
\hline MIN & $-1,51$ & $-2,08$ & $-2,10$ & 0,10 \\
\hline MAX & 2,66 & 8,11 & 0,69 & 0,53 \\
\hline RANGE & 4,16 & 10,19 & 2,79 & 0,43 \\
\hline AVERAGE & 0,97 & 3,43 & $-1,07$ & 0,36 \\
\hline STDEV & $\pm 1,22$ & $\pm 3,46$ & $\pm 0,87$ & $\pm 0,15$ \\
\hline
\end{tabular}

For the geomagnetic survey carried out by the variometer method, according to the IAGA recommendations [1] applies the following: variations of the vector magnetic field in the vicinity of the repeat station are determined continuously for 3 or more days of low magnetic activity and calibrated to an accuracy of 5 nT. The analysis of each baseline component standard deviation reported in Tab. 1 proves that the predefined baselines accuracy was fulfilled. Hence, the baseline components average values were accepted as definitive and subsequently the $X Y Z F$ elements were reduced from dIdD station to the repeat station.

\section{Determination of the geomagnetic field Quiet-Time Level}

During the Quiet-Time conditions the impact of the external field sources on the observed geomagnetic elements is lower and consequently their differences between the repeat station and reference observatory are more stable providing a more reliable time data reduction. The record of the variometer gives a perfect chance to monitor the diurnal variation of the difference between the reference observatory and the repeat station. It is well 
known that the geomagnetic field is the quietest during the night-time that was proven by the first geomagnetic night-time survey at the POKU repeat station [19], but the least disturbed night-time field does not necessarily occur at the 02 UTC epoch. Thus, the quiet-time level field was determined from the 60 minutes long sliding windows (as suggested in [20]) of the geomagnetic elements difference between the SINP repeat station and THY reference observatory. The quiet-time level determination according to $|\mathrm{STDEV}|<0,2 \mathrm{nT}$ criterion for each $X Y Z F$ geomagnetic element [20] identified four periods including altogether 263 minute mean values. Due to $373 \mathrm{~km}$ distance between the SINP repeat station and THY observatory, the criterion was relaxed to $|\mathrm{STDEV}|<0,3 \mathrm{nT}$ per each $X Y Z F$ element resulting in the identification of 12 periods with altogether 985 minute mean values.

For each period the average values of the geomagnetic elements $(X Y Z F)$ differences were calculated along with their minimum, maximum and range values. During the definitive Quiet-Time Level calculation as the average value of all 12 periods it was noticed the occurrence of some unacceptably high STDEV and range values. Further examination evidenced that $Y$ and $Z$ component in the $1^{\text {st }}$ and $2^{\text {nd }}$ periods exhibited significant deviations, thus these periods were excluded from the calculations of the definitive Quiet-Time Level differences between the SINP and THY. The definitive Quiet-Time Level values determined from the periods $\left(3^{\text {rd }}\right.$ $\div 12^{\text {th }}$ ) along with the corresponding statistical quantities are reported in Tab. 2.

Table 2 Definitive values of the Quiet-Time Level of the geomagnetic element differences between SINP repeat station and THY observatory

\begin{tabular}{|c|c|c|c|c|}
\hline $\begin{array}{c}\text { Geomagnetic } \\
\text { element }\end{array}$ & $X / \mathrm{nT}$ & $Y / \mathrm{nT}$ & $Z / \mathrm{nT}$ & $F / \mathrm{nT}$ \\
\hline MIN & 1677,54 & $-162,40$ & $-2066,90$ & $-1041,46$ \\
\hline MAX & 1679,57 & $-160,69$ & $-2065,90$ & $-1039,72$ \\
\hline RANGE & 2,03 & 1,71 & 1,00 & 1,74 \\
\hline AVERAGE & 1678,56 & $-161,85$ & $-2066,43$ & $-1040,68$ \\
\hline STDEV & $\pm 0,75$ & $\pm 0,51$ & $\pm 0,29$ & $\pm 0,53$ \\
\hline
\end{tabular}

Differences of the geomagnetic element $(X Y Z F)$ minute mean values between the SINP repeat station and THY observatory during the SINP occupation $(23 \div 27$ July 2010) are shown in Fig. 3.
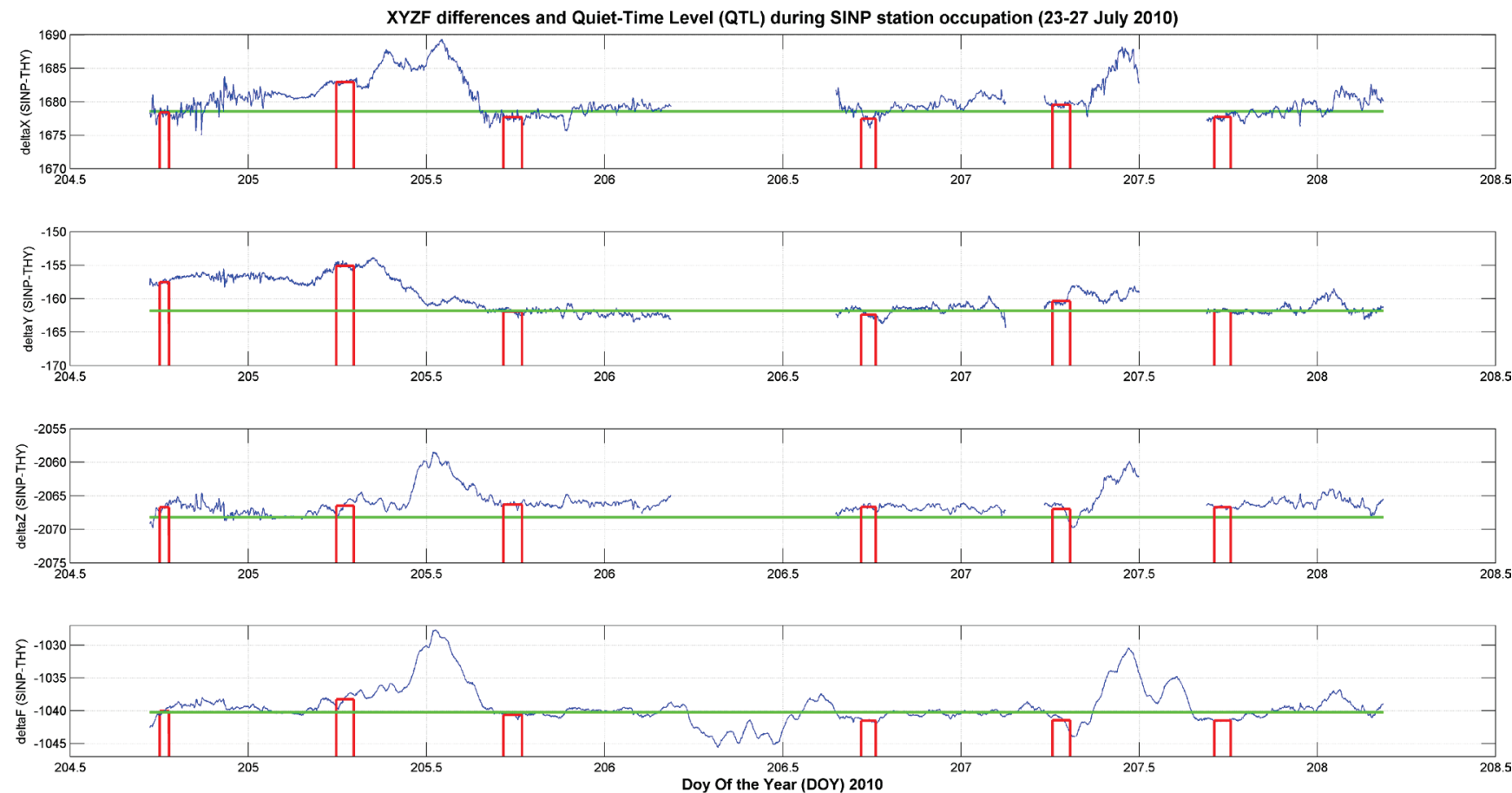

Figure 3 Geomagnetic element $(X Y Z F)$ differences between the SINP repeat station and THY observatory during the SINP station occupation $(23 \div 27$ July 2010). The green lines represent the Quiet-Time Level, the red columns show the average difference values during the absolute set sessions on the SINP repeat station

The gaps in the geomagnetic element differences plot (Fig. 3) are due to the noisy data that were excluded from further consideration. As it was expected, the geomagnetic element differences are higher during the daytime than during the night-time exhibiting the maximum values around the noon. The green horizontal line in Fig. 3 represents the Quiet-Time Level for each geomagnetic element $(X Y Z F)$ difference, the red columns show the average difference values during the absolute set sessions on the SINP repeat station.

As shown in Fig. 3, during the SINP repeat station occupation, the absolute sets were observed in 6 sessions (one session is not shown because of the lack of simultaneous variometer data). For each absolute set session, the average value of the geomagnetic elements difference between the SINP repeat station and THY observatory was calculated. The difference between those average values and the Quiet-Time Level for each absolute set session corresponds to the potential error of the data reduction in the case the geomagnetic survey was carried out without an onsite variometer [20]. Departures of the average values of the geomagnetic element difference (SINP-THY) for all absolute set sessions (red columns) from the Quiet-Time Level are in the range: 
$-1,11 \mathrm{nT}$ to $4,40 \mathrm{nT}$ for $X,-0,54 \mathrm{nT}$ to $6,76 \mathrm{nT}$ for $Y$, $-0,55 \mathrm{nT}$ to $0,14 \mathrm{nT}$ for $Z$ and $-0,87 \mathrm{nT}$ to $2,41 \mathrm{nT}$ for $F$. Since the difference of the instantaneous minute mean values has a direct influence on the reduced data value, it is clear that the geomagnetic survey carried out during the times with smaller geomagnetic elements differences leads to a more reliable reduction results

\section{Data reduction of SINP repeat station}

Minute mean values as well as the annual mean for the year 2010 of the Tihany (THY) reference observatory data were used for data reduction of the SINP repeat station. The absolute geomagnetic elements were observed at the SINP repeat station through 33 absolute sets performed in 6 sessions. Some parts of three out of 6 sessions took place within the time periods with $|\mathrm{STDEV}|<0,3 \mathrm{nT}\left(2^{\text {nd }}, 5^{\text {th }}\right.$ and $6^{\text {th }}$ period $)$. The $2^{\text {nd }}$ period (occurring simultaneously with $2^{\text {nd }}$ session, see Fig. 3 ) had to be excluded from the final Quiet-Time-Level due to its anomalous behaviour i.e departure from the Quiet-Time Level. All absolute sets from $5^{\text {th }}$ and $6^{\text {th }}$ session took place within the periods with $|\mathrm{STDEV}|<0,3 \mathrm{nT}$ showing small departure from the Quiet-Time-Level (Fig. 3).

For the data reduction was used a simple model (Model I) assuming that the difference of the geomagnetic elements annual mean values at the repeat station and reference observatory equals to the instantaneous difference of the same elements [1]. From Fig. 3 it can be clearly seen that the instantaneous differences of the geomagnetic elements are not constant, however, there are periods during the day when those differences are more stable enabling a more reliable data reduction. Besides the daily variation, the instantaneous differences of the geomagnetic elements are affected by the secular variation difference between the repeat station and reference observatory. Within the data reduction Model I, the secular variation difference was not taken into consideration. However, since the geomagnetic survey was carried out close to the middle of the year (epoch 2010,5) which the data are reduced to, the error caused by secular variation difference at the repeat station and reference observatory was neglected [1].

For the data reduction (Model I) applies the following equation
$E_{\mathrm{rs}}(t)-E_{\mathrm{rs}}(2010,5)=E_{\mathrm{obs}}(t)-E_{\mathrm{obs}}(2010,5)$,

where $E_{\mathrm{rs}}(t)$ and $E_{\mathrm{rs}}(2010,5)$ are the geomagnetic element $E$ values at the repeat station in the time $t$ and annual mean epoch 2010,5, respectively. Similarly, $E_{\text {obs }}(t)$ and $E_{\text {obs }}(2010,5)$ are the same quantities of the reference observatory. From the Eq. (12), the geomagnetic element annual mean on the repeat station was calculated according to

$$
E_{\mathrm{rs}}(2010,5)=E_{\mathrm{obs}}(2010,5)+\left\{E_{\mathrm{rs}}(t)-E_{\mathrm{obs}}(t)\right\} .
$$

Taking into consideration all of the 33 absolute sets and THY annual means, the geomagnetic elements of the SINP repeat station reduced values to the epoch 2010,5 are given in Tab. 3 (left side). Definitive reduced data were calculated as the average value. Along with the standard deviation (STDEV), the accuracy was expressed in the form of scatter as suggested by the MagNetE Working group. The scatter is defined as follows $(E$ represents a geomagnetic element, $A V E$ represents its average value)

SCATTER $=\max \{(E-A V E) \mid\}$.

Similarly to the Eq. (13), instead of the instantaneous geomagnetic element differences, the difference between the annual means at the repeat station and reference observatory should be equal to the difference of the corresponding geomagnetic elements during the quiet time i.e. Quiet-Time Level. Hence, the Eq. (13) can be written as

$$
E_{\mathrm{rs}}(2010,5)=E_{\mathrm{obs}}(2010,5)+\left\{E_{\mathrm{rs}}-E_{\mathrm{obs}}\right\}_{\mathrm{QTL}} \text {, }
$$

where QTL denotes the Quiet-Time Level. The geomagnetic elements value reduced according to the Eq. (15) along with the accuracy estimation are shown in Tab. 3 (right side). The accuracy estimation was derived from the statistics of the magnetic field differences between SINP and THY obtained from $3^{\text {rd }} \div 12^{\text {th }}$ periods exhibiting $|\mathrm{STDEV}|<0,3 \mathrm{nT}$. Standard deviations of differences in $X Y Z F$ between SINP and THY (Tab. 2) show the same values as in Tab. 3 (right side).

Table 3 SINP repeat station data reduced to the epoch 2010,5 according to the data reduction Model I and THY reference observatory data (left side); SINP repeat station data reduced to the epoch 2010,5 and Quiet-Time Level (right side)

\begin{tabular}{|c|c|c|c|c|c|c|}
\hline Data reduction model & \multicolumn{3}{|c|}{ Model I } & \multicolumn{3}{c|}{ Quiet-Time Level } \\
\hline Geomagnetic element & AVERAGE & STDEV & SCATTER & AVERAGE & STDEV & SCATTER \\
\hline$D /{ }^{\circ} \prime \prime$ & $2^{\circ} 52^{\prime} 32^{\prime \prime}$ & $\pm 0^{\circ} 00^{\prime} 15^{\prime \prime}$ & $0^{\circ} 00^{\prime} 34^{\prime \prime}$ & $2^{\circ} 52^{\prime} 20^{\prime \prime}$ & $\pm 0^{\circ} 00^{\prime} 06^{\prime \prime}$ & $0^{\circ} 00^{\prime} 08^{\prime \prime}$ \\
\hline$I /^{\circ} \prime \prime$ & $60^{\circ} 29^{\prime} 35^{\prime \prime}$ & $\pm 0^{\circ} 00^{\prime} 06^{\prime \prime}$ & $0^{\circ} 00^{\prime} 15^{\prime \prime}$ & $60^{\circ} 29^{\prime} 40^{\prime \prime}$ & $\pm 0^{\circ} 00^{\prime} 02^{\prime \prime}$ & $0^{\circ} 00^{\prime} 04^{\prime \prime}$ \\
\hline$X / \mathrm{nT}$ & 23166,53 & $\pm 1,52$ & 3,10 & 23166,56 & $\pm 0,75$ & 1,02 \\
\hline$Y / \mathrm{nT}$ & 1163,67 & $\pm 1,55$ & 3,18 & 1162,15 & $\pm 0,51$ & 1,15 \\
\hline$Z / \mathrm{nT}$ & 40986,63 & $\pm 1,53$ & 3,22 & 40987,57 & $\pm 0,29$ & 0,54 \\
\hline$F / \mathrm{nT}$ & 47095,08 & $\pm 1,81$ & 3,85 & 47095,32 & $\pm 0,53$ & 0,96 \\
\hline
\end{tabular}

The analysis of the two applied reduction models (Tab. 3) led to the data reduction result differences (QTL - Model I) as follows: $\Delta D=-12^{\prime \prime}\left(\mathrm{STDEV}= \pm 15^{\prime \prime}\right), \Delta I=$ $5 "(\mathrm{STDEV}= \pm 6 "), \Delta X=0,03 \mathrm{nT}(\mathrm{STDEV}= \pm 1,52 \mathrm{nT})$, $\Delta Y=-1,52 \mathrm{nT}(\mathrm{STDEV}= \pm 1,55 \mathrm{nT}), \Delta Z=0,94 \mathrm{nT}$ $(\mathrm{STDEV}= \pm 1,53 \mathrm{nT})$ and $\Delta F=0,24 \mathrm{nT}(\mathrm{STDEV}=$ $\pm 1,81 \mathrm{nT})$. By the comparison of data reduction results accuracy (STDEV and SCATTER) it can be concluded, as expected, that data reduction to a Quiet-Time Level provided a more reliable results. Moreover, the differences between two data reduction models are within 
the STDEV accuracy estimation of the data reduced according to Model I.

In addition to the two applied data reduction methods, the so-called reduction to a quiet level was tested too. According to the method's explanation given in [21], quiet-time values were selected by examining the data from the THY observatory for the eleven-day period centered on the observation day. The quiet night-time value for THY observatory was taken to be the mean of the two hourly means either side of midnight from two days showing minimal external field disturbance. The hours of minimal irregular external field disturbance were selected by finding the minimal sum of standard deviations of geomagnetic elements. For each observation day $(23 \div 26$ July 2010$)$ the quiet level was found and subsequently the data reduction was carried out. Geomagnetic elements reduced to each observation day were obtained, but for the sake of comparability with other data reduction results, the daily solutions were reduced to the 2010,5 epoch using the annual change of the geomagnetic elements for SINP repeat station [7]. The final reduced data values calculated as average along with the accuracy estimation are shown in Tab. 4 (left side). Although the reduced geomagnetic element accuracy estimation is acceptable $\left(<1^{\prime}\right.$ for $D, 0,5^{\prime}$ for $I$ and $<5 \mathrm{nT}$ for other components [1]), reduced values exhibit a difference from the reduction results given in Tab. 3 .

Data reduction model using the onsite variometer presented in [22] consists of two steps: firstly, the data are reduced to the $02 \mathrm{UTC}$ epoch at VAR station of the day of observation and subsequently reduced to the reference observatory annual mean epoch using the observatory data related to the epoch 02 UTC of the same day of observation. This data reduction method was carried out with THY reference observatory data leading to the results presented in Tab. 4 (right side). The statistical parameters of data reduction according to [22] were derived from the independent reductions of absolute sets observed during four days of SINP repeat station occupation.

Table 4 SINP repeat station data reduced to a quiet level and 2010.5 according to [21] (left side); SINP repeat station data reduced to the epoch 2010,5 according to [22]

\begin{tabular}{|c|c|c|c|c|c|c|}
\hline Data reduction model & \multicolumn{3}{|c|}{ According to [21] } & \multicolumn{3}{c|}{ According to [22] } \\
\hline Geomagnetic element & AVERAGE & STDEV & SCATTER & AVERAGE & STDEV & SCATTER \\
\hline$D / /^{\prime \prime \prime}$ & $2^{\circ} 52^{\prime} 14^{\prime \prime}$ & $\pm 0^{\circ} 00^{\prime} 18^{\prime \prime}$ & $0^{\circ} 00^{\prime} 25^{\prime \prime}$ & $2^{\circ} 52^{\prime} 42^{\prime \prime}$ & $\pm 0^{\circ} 00^{\prime} 25^{\prime \prime}$ & $0^{\circ} 00^{\prime} 59^{\prime \prime}$ \\
\hline$I /^{\circ} \prime^{\prime \prime}$ & $60^{\circ} 29^{\prime} 01^{\prime \prime}$ & $\pm 0^{\circ} 00^{\prime} 03^{\prime \prime}$ & $0^{\circ} 00^{\prime} 03^{\prime \prime}$ & $60^{\circ} 29^{\prime} 29^{\prime \prime}$ & $\pm 0^{\circ} 00^{\prime} 08^{\prime \prime}$ & $0^{\circ} 00^{\prime} 14^{\prime \prime}$ \\
\hline$X / \mathrm{nT}$ & 23175,81 & $\pm 0,94$ & 1,39 & 23168,67 & $\pm 1,34$ & 2,38 \\
\hline$Y / \mathrm{nT}$ & 1162,96 & $\pm 2,14$ & 2,62 & 1164,97 & $\pm 2,83$ & 6,68 \\
\hline$Z / \mathrm{nT}$ & 40986,48 & $\pm 1,15$ & 1,46 & 40986,60 & $\pm 0,91$ & 1,94 \\
\hline$F / \mathrm{nT}$ & 47099,20 & $\pm 1,95$ & 2,32 & 47095,85 & $\pm 0,15$ & 0,23 \\
\hline
\end{tabular}

Difference in declination $\Delta D=22^{\prime \prime}$ reduced according to different reduction models (Reduction model according to [22] - Quiet-Time Level) (Tab. 4 - right side and Tab. 3 - right side) is related to the scatter of $D\left(59^{\prime \prime}\right)$ reduced according to [22]. The same applies for the $Y$ component. By comparison of the accuracy estimations of both data reduction method results (Quiet-Time Level and Reduction model according to [22]) it can be inferred that it is more reliable to determine a Quiet-Time Level in reference to geomagnetic observatory, rather than rely on the predefined instant (epoch) (in this case 02 UTC).

Table 5 SINP repeat station data reduced to 2010,5 according to Model I and observatories CTS, FUR, GCK, PAG and THY

\begin{tabular}{|c|c|c|c|}
\hline $\begin{array}{c}\text { Geomagnetic } \\
\text { element }\end{array}$ & AVERAGE & STDEV & SCATTER \\
\hline$D / /^{\prime \prime} "$ & $2^{\circ} 52^{\prime} 30^{\prime \prime}$ & $\pm 0^{\circ} 00^{\prime} 13^{\prime \prime}$ & $0^{\circ} 00^{\prime} 16^{\prime \prime}$ \\
\hline$I /^{\circ} \prime \prime$ & $60^{\circ} 29^{\prime} 33^{\prime \prime}$ & $\pm 0^{\circ} 00^{\prime} 09^{\prime \prime}$ & $0^{\circ} 00^{\prime} 15^{\prime \prime}$ \\
\hline$F / \mathrm{nT}$ & 47095,85 & $\pm 0,36$ & 0,50 \\
\hline
\end{tabular}

Moreover, in data reduction Model I, along with THY observatory data, four additional observatories surrounding the Croatian territory were included: CTS (Castello Tesino) in Italy, FUR (Fuerstenfelbruck) in Germany, GCK (Grocka in Serbia) and PAG (Panagyurishte) in Bulgaria. The representative values of the reduced geomagnetic elements were given in the form of the simple arithmetic mean as well as the weighted arithmetic mean including all observatories. The average values of the reduced $D, I$ and $F$ taking into consideration all observatories, along with the accuracy estimation are given in Tab. 5 .
The weighting factors were determined as reciprocal values of the square standard deviation of the geomagnetic element difference between SINP repeat station and each observatory according to the explained in [7]. The weighted average of the reduced $D, I$ and $F$ using all observatories data were given as follows: $D=2^{\circ} 52^{\prime}$ $31^{\prime \prime}, I=60^{\circ} 29^{\prime} 35^{\prime \prime}$ and $F=47095,27 \mathrm{nT}$ showing small differences with reduced values given in Tab. 5. The inclusion of additional observatories in data reduction procedure enables a more reliable reduced geomagnetic element results.

The comparison of different reduction method results has emphasized the reduction to a Quiet-Time Level perhaps as the most reliable data reduction method.

\section{Conclusions}

The temporal variability of the geomagnetic element differences between the repeat station and the dIdD station caused most likely by an extra magnetic field as a result of the high conductivity contrast e.g. between the sea and the mainland, indeed could represent a limitation for geomagnetic survey using the onsite variometer. As the result of a long station occupation and a large number of absolute sets it was possible to find a Quiet-Time Level allowing on the other hand the improvement of the data reduction reliability. The application of the onsite variometer has pointed out that the geomagnetic survey has to be performed during the periods with high stability of the geomagnetic element differences between the repeat station and reference observatory. Such situations occur in absence of geomagnetic storms, during the early 
morning times, late afternoon times or even better during the night-time, and finally in the absence of the extra magnetic field sources. Although in this paper the presence and impact of an extra magnetic field has been identified, further research should be oriented toward the survey, modelling and removal of the extra magnetic field influence on observations of the geomagnetic field. Among the tested data reduction methods, the reduction to the Quiet-Time-Level can be regarded as the most reliable with the best accuracy estimation of the reduced geomagnetic elements.

\section{Acknowledgements}

The authors acknowledge the Ministry of Science, Education and Sports, the Institute for Research and Development of Defence Systems of the Ministry of Defence and State Geodetic Administration of the Republic of Croatia as well as the Faculty of Geodesy of the University of Zagreb. The results presented in this paper rely on the data collected at Tihany (THY) observatory. We thank the Geological and Geophysical Institute of Hungary for supporting the operation of THY observatory and INTERMAGNET for promoting high standards of magnetic observatory practice.

\section{References}

[1] Newitt, L. R.; Barton, C. E.; Bitterly, J. Guide for Magnetic Repeat Stations Survey. International Association of Geomagnetism and Aeronomy, Boulder, USA, 1996.

[2] Sas-Uhrynowski, A.; Korte, M.; Schott, J-J.; Schwarz, G. Recommendations for European Magnetic Repeat Station Surveys. // Coordination Committee for common European repeat station surveys. 2003. URL: http://www-app3.gfzpotsdam.de/eurepstat/repstat/recommendation.pdf (18.02.2014).

[3] Brkić, M.; Sugar, D.; Pavasović, M.; Vujić, E.; Jungwirth, E. Croatian geomagnetic field maps for 2008.5 epoch. // Annals of Geophysics. 55, 6(2012), pp. 1061-1069.

[4] Osnovna geomagnetska mreža Republike Hrvatske i geomagnetske izmjere 2004-2012. // Osnovna geomagnetska mreže Republike Hrvatske 2004-2012 s kartama geomagnetskog polja za epohu 2009.5 / Šugar, D; Rezo, M.; Pavasović, M.; Šljivarić, M.; Bjelotomić, O. (ur. Brkić, M.) Zagreb : Republika Hrvatska, Državna geodetska uprava, 2013. pp. 10-20.

[5] Brkić, M.; Šugar, D.; Pavasović, M. The Representative Recent Secular Variation of the Geomagnetic Field on the Croatian Territory. // Proceedings of the International conference on Magnetism, Geomagnetism and Biomagnetism - MGB 2008/ Sežana, 2008, pp. 49-57.

[6] Brkić, M.; Vujić, E. Sekularna varijacija geomagnetskog polja na teritoriju Hrvtaske. // Geodetski list. 64 (87), 1(2010), pp. 1-9.

[7] Redukcije izmjera, normalna polja i godišnje promjene 2004.-2012. // Osnovna geomagnetska mreža Republike Hrvatske 2004-2012 s kartama geomagnetskog polja za epohu 2009.5 / Vujić, E.; Brkić, M.; Bjelotomić, O.; (ur. Brkić, M.) Zagreb : Republika Hrvatska, Državna geodetska uprava, 2013. pp. 21-32.

[8] Šugar, D.; Bašić, T.; Bačić, Ž. Azimuth determinations and analysis on the repeat stations network in Croatia. // Proceedings of the International Multidisciplinary Scientific Conference SGEM 2012, Volume II / Albena, Bulgaria, 2012, pp. 693-700.
[9] Csontos, A.; Šugar, D.; Brkić, M.; Kovács, P.; Hegymegi, L. How to control a temporary DIDD based observatory in the field? // Annals of Geophysics. 55, 6(2012), pp. 10851094.

[10] Kovács, P.; Brkić, M.; Vujić, E.; Csontos, A.; Vadász, G.; Šugar D. A Croatian-Hungarian Magnetic Reference Field Model. $/ / 6^{\text {th }}$ MagNetE Workshop on European geomagnetic repeat station survey, poster presentation / Prague, Czech Republic, 3-5 June 2013.

[11] Kovács, P.; Vujić, E.; Csontos, A.; Brkić, M.; Heilig, B.; Koppan A. Regional magnetic field model for Croatia and Hungary. $/ / 6^{\text {th }}$ Congress of Balkan Geophysical Society Budapest, Hungary, 2011.

[12] Csontos, A.; Šugar, D.; Brkić, M.; Kovács, P. Experiences of Joint Croatian-Hungarian Geomagnetic Repeat Station Survey. $/ / 5^{\text {th }}$ MagNetE Workshop on European geomagnetic repeat station survey, poster presentation, Roma, Italy, 2011.

[13] Heilig, B. Intercalibration of dIdD and fluxgate magnetometers. // Publications of the Institute of Geophysics Polish Academy of Sciences. C-99 (398) / Warszaw, Poland, 2007, pp. 146-153.

[14] Heilig, B.; Csontos, A.; Pajunpää, K.; Gouws, D.; White, T.; St-Louis, B.; Calp, D. Measuring the Orthogonality Error of Coil Systems. // Proceedings of the $\mathrm{XV}^{\mathrm{th}}$ IAGA Workshop on Geomagnetic Observatory Instruments, Data Acquisition, and Processing / San Fernando, Spain,2012, pp. $42-45$.

[15] Jankowski, J.; Sucksdorff, C. Guide for magnetic measurements and observatory practice. International Association of Geomagnetism and Aeronomy, Boulder, USA, 1996.

[16] DIM Declination/Inclination Theodolite Operational Manual version 1.2a. Mingeo, Budapest, Hungary, 2005.

[17] Brkić, M. Završno izvješće o radu na projektu Joint Croatian-Hungarian Geomagnetic Repeat Stations Survey and Joint Geomagnetic Field Model. MZOS, 2011.

[18] Csontos, A. Leader of Tihany Geophysical Observatory, Private communication, 2014.

[19] Šugar, D.; Varga, M.; Cindrić, M. Noćna opažanja geomagnetskog polja na sekularnoj točki POKUpsko. // Geodetski list. 67, 1(90)(2013), pp. 13-27.

[20] Kovács, P.; Csontos, A.; Heilig, B.; Koppán, A. Hungarian repeat station survey, 2010. // Annals of Geophysics. 55, 6(2012), pp. 1113-1119.

[21] Shanahan, T. J. G.; Swan, A. P.; Macmillan, S. UK 20092010 repeat station report. // Annals of Geophysics. 55, 6(2012), pp. 1155-1160.

[22] Dominici, G.; Meloni, A.; Miconi, M.; Pierozzi, M.; Sperti, M. Italian Magnetic Network and Geomagnetic Field Maps of Italy at year 2005.0. // Bolletino di Geodesia e Scienze Affini, Anno LXVI, N. 1, January-February-March 2007, Istituto Geografico Militare, Firenze, Italy.

\section{Authors' addresses}

Danijel Šugar, Ph.D., research assistant Mario Brkić, full professor of the Faculty of Geodesy

Faculty of Geodesy, University of Zagreb Kačićeva 26, HR-10 000 Zagreb, Croatia E-mail: dsugar@geof.hr

E-mail: mbrkic@geof.hr

András Csontos, MSc, leader of Tihany Geophysical Observatory Geological and Geophysical Institute of Hungary, Tihany Geophysical Observatory

Kossuth L. u., H-8237 Tihany, Hungary

E-mail: csontos.andras@mfgi.hu 